\title{
Effects of intention and learning on attention to information in dynamic touch
}

\author{
Ryan Arzamarski, Robert W. Isenhower, Bruce A. KaY, \\ M.T. Turvey, and Claire F. Michaels \\ University of Connecticut, Storrs, Connecticut
}

\begin{abstract}
The current research distinguishes two types of attention shifts: those entailed by perceptual learning and those entailed by changing intention. In perceptual learning, participants given feedback have been shown to gradually shift attention toward the optimal (i.e., specifying) information variable for the task. A shift in variable use is also expected when intention changes, because an intention to perceive some property entails attunement to information about that property. We compared the effects of feedback and intention in a dynamic (kinesthetic) touch task by representing both as changes of locus in an information space of inertial variables. Participants wielded variously sized, unseen, rectangular parallelepipeds and made length or width judgments about them. When given feedback, participants made gradual attentional shifts toward the optimal variable, which demonstrates the education of attention. When asked to report a new property, participants made large attentional jumps to the ballpark of the optimal variable for the new property. Exploratory movements were measured on 6 participants and were found to differ as a function of intention and to change with learning.
\end{abstract}

Successful action requires an animal to be in touch with its environment - to be able to perceive properties relevant to the accomplishment of the task at hand. Ecological psychology, the perspective adopted here, holds that patterns of stimulation embody information about these properties. Success at a task, then, implies attunement to such information, which may involve learning, or what the Gibsons called the education of attention (E. J. Gibson, 1969; J. J. Gibson, 1966). Asking perceivers to report on some property, then informing them of the actual value of the property, is one way to evoke changes in attunement and has been explicitly investigated in several recent studies (e.g., Jacobs, Runeson, \& Michaels, 2001; Michaels, Arzamarski, Isenhower, \& Jacobs, 2008; Michaels \& de Vries, 1998; Smith, Flach, Dittman, \& Stanard, 2001).

The education of attention, however, cannot be the only process associated with a change in attunement, because perceiver-actors must achieve a large and diverse set of goals, each goal with its own informational basis. As a perceiver progresses from one goal-oriented action to the next, attention must rapidly shift among informational variables. Perceivers face the recurring challenge of turning themselves into appropriate information-detection devices (Turvey, 1988). Such shifts in intention, then, are a second factor that affects what information a perceiveractor will pick up. Given an intention to perceive some property, the attunement to certain information is entailed. Demonstrating this relationship has been thwarted by the lack of techniques for identifying the particular information that a perceiver is attending to, and how that attunement changes. Such techniques are becoming available; so, in what follows, we ask whether a change in intention expresses itself as informational reattunement. Although our primary interest is in learning and intention switching, we note, for completeness, that there is a third basis for changes in attunement. Attention can also be at the beck and call of environmental information: Information about certain events can draw attention. Such information is said to have attensity (see Shaw \& McIntyre, 1974).

We consider the effects of switching intention and educating attention using Jacobs and Michaels's (2007) ecological theory of perceptual learning, which they term $d i-$ rect learning. The theory has two key postulates: The first is that the variables that might lay an informational basis for a task constitute a continuous information space, and the second is that perceptual learning is an informationally guided movement through the space. For present purposes, information space provides a convenient means of measuring how changing intention and perceptual learning affect information use. The choice of experimental task derives from our recent application of direct learning to the dynamic touch paradigm (Michaels et al., 2008). In sum, the goal of the present contribution is to examine how changes in intention affect attunement within an information space for dynamic touch and to contrast these with changes attributable to ongoing learning. We now provide details on these theoretical and methodological starting points.

\section{The Role of Intention in Perception}

One might expect that to run an experiment examining the effects of intention would require a full-fledged theory of intention. That we do not have, and it must suffice to

R. Arzamarski, ryanarz91@gmail.com 
manipulate intention simply by asking experimental participants to report a property. Nevertheless, we would like to convey our general appreciation of the intentional character of perception. The full-fledged theory should address how and when intentions arise, as well as how they manifest themselves in the activities of the perceiver-actor. As to how intentions arise, we find the most promising starting point to be Iberall's (1977; Iberall \& McCulloch, 1969) idea that living things comprise a limited number of nonlinear thermodynamic oscillators, and cycle among their associated action modes - eating, sleeping, voiding, and so on - and that these modes entail goal-directed actions: finding a restaurant, a bed, a toilet, and so on. Of course, one must learn about restaurants, beds, and toilets; education of intention is about establishing such goalslearning about tasks and their solutions. ${ }^{1}$

Intention plays its role by setting up a perception system to be receptive to- "to resonate to" in J. J. Gibson's (1966) language - information appropriate for the to-be-perceived property or for the to-be-undertaken action. In other words, intention directs attention. Appreciating the circular causality of perception and action makes this more concrete: Intentions motivate explorations that constrain perception, which further constrains action, and so on. Pulling this together, we suppose that the instruction to report the width, say, of an unseen, wielded object entails a certain type of exploratory movement (or what Lederman \& Klatzky, 1987, 1990, labeled an exploratory procedure, such as rubbing for texture or squeezing for pliability). To say that a perceiver knows of width through wielding is to say that he or she has an appropriate exploratory movement.

To understand the character of an exploratory movement, we take a page from the work of Greene (e.g., 1972), who emphasized that a purposive action, presumably including exploration for some property, constitutes a family of possible activities. Intention, then, can be interpretable as feedforward in Greene's sense:

The feedforward [has] only to bring the state of the system "into the right ballpark," i.e., into some broad class of states, within which feedback could automatically bring the system the rest of the way to the exact state required. (p. 311)

These general considerations of the co-implication of intention, information, and exploration have been distilled into the co-specificity hypothesis (Turvey, Carello, \& Kim, 1990): Initial exploratory actions entailed by the intention to perceive some property are expected to reveal information about that property, or, in terms of the approach adopted in this article, to land one in the task's information space.

\section{Information Space and Dynamic Touch}

It is possible to create a space containing all information variables relevant for some particular perceptual or perceptual-motor task; as noted, this space has been termed an information space (Jacobs \& Michaels, 2007). ${ }^{2}$ The space is a continuous collection of loci, where each locus represents an information variable to which a perceiver might attend. These loci differ in their level of usefulness regarding the to-be-perceived property. The optimal variable in the space is the locus that, if it were attended to over a series of trials, would yield maximally accurate perceptual judgments or actions. At any point in time, a perceiver is said to occupy some locus; that is, he or she exploits some particular variable.

Presumably, a perceiver's initial locus in the space when starting a new task is dictated by intention and learning history. When the consequences of actions or extrinsic feedback about judgments are available, the perceiver is expected to learn - that is, to traverse the space in the direction of the optimum (see Figure 1). Movement in the information space, therefore, represents a change in which variable the perceiver is attending to. According to the theory of direct learning, action consequences and feedback make available systematicities between errors and other variables. These systematicities push perceivers toward the optimum (Jacobs \& Michaels, 2007). Concrete examples of such information and such movement have been reported in the dynamic touch paradigm by Michaels et al. (2008) and Jacobs, Silva, and Calvo (2009). Although we hoped to replicate the general finding of convergence on an optimal variable, our main goal was to measure how intention affects a perceiver's locus in information space and to compare such effects with those observed in the perceptual learning process. We now illustrate information space and learning by elaborating our previous work in dynamic touch, beginning with a brief and general review of the paradigm.

When one hefts or wields an object, the object's properties can be perceived. This is termed kinesthetic or dynamic touch; we use the latter term. Wielding an object exerts reactive forces and torques on skin, muscles, ligaments, and tendons. From this array of stimulation, perceivers can detect information that specifies properties such as length, width, and crude shape (for summaries, see Carello \& Turvey, 2004; Turvey, 1996). Typically, investigations of the informational basis of such perceptions require partici-

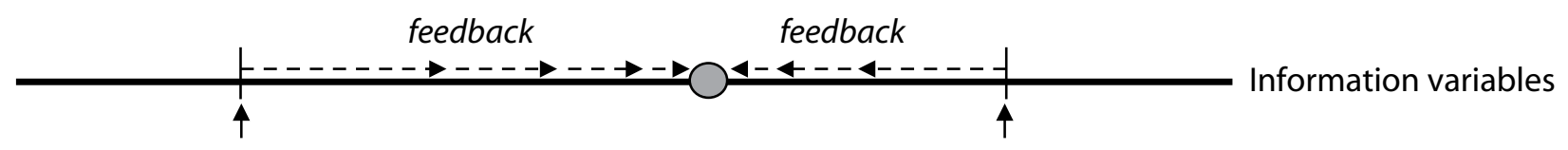

Perceiver 1 initial attunement

Perceiver 2 initial attunement

Figure 1. One-dimensional information space showing hypothetical learning by two perceivers. Each point on the line is a different information variable. The circular point represents the optimum, the most useful information for the to-be-perceived property. Perceivers move toward the optimum when provided feedback over blocks of trials. Movement, as depicted by the dashed arrows, represents a gradual change in attunement toward a more useful information variable. 
pants to make judgments about a certain property from wielding a series of unseen, handheld objects.

There are several considerations in defining an information space for dynamic touch (or any perceptual system). For an information space to be complete, it must contain all the candidate information variables that a perceiver might exploit to accomplish the tasks at hand. ${ }^{3}$ As a first pass on meeting this conceptual requirement, we include variables implicated by previous research. In the case of dynamic touch, the moments of an object's mass distribution have been so implicated: Various perceived properties, including length (Kingma, Beek, \& van Dieën, 2002; Solomon \& Turvey, 1988), width (Turvey, Burton, Amazeen, Butwill, \& Carello, 1998), a racquet's sweet spot (Carello, Thuot, Anderson, \& Turvey, 1999), and crude shape (Burton, Turvey, \& Solomon, 1990) have been shown to depend on mass moments.

Michaels et al. (2008) showed that a space derived from the first and third principal moments of inertia $\left(I_{1}\right.$ and $\left.I_{3}\right)$ was sufficient to capture information usage as perceivers learned to judge the lengths of wielded, unseen rods and pipes. An object's first principal moment of inertia is its maximal resistance to acceleration about an axis through the point of rotation. The second principal moment is about that axis perpendicular to the first that has the next highest resistance. The third principal moment of inertia has the smallest resistance to rotational acceleration and is about an axis orthogonal to the other two. We follow Michaels et al.'s (2008) convention of a one-dimensional information space.

The information space should capture all possible nonredundant ratios and products of $I_{1}^{a}$ and $I_{3}^{b}$. Redundant ratios and products would be those that are perfectly correlated with each other. For example, say that a perceiver's judgments were based on $I_{1}^{4} / I_{3}^{2}$. Ignoring the scaling factor, $\ln ($ judgment $)=\ln \left(I_{1}^{4} / I_{3}^{2}\right)$, which expands to $\ln ($ judgment $)=4 \times \ln \left(I_{1}\right)+2 \times \ln \left(I_{3}\right)$. One would get the same correlation of judgments and information if $a=2$ and $b=1$, so we treat these as the same information variable and capture the identity by projecting the line of equivalent points on a circle, as explained in Figure 2, leaving us with Equation 1:

$$
E_{\alpha}=\cos (\alpha) \times \ln \left(I_{1}\right)+\sin (\alpha) \times \ln \left(I_{3}\right) .
$$

Any particular information variable is identified as locus $\alpha . E_{\alpha}$, in turn, is the value of the information variable for a particular stimulus at a particular locus; so, using the equation, one can determine for each locus the collection of information values corresponding to the stimulus objects on the basis of their $I_{1} \mathrm{~s}$ and $I_{3}$ s. Note that at $\alpha=0$, the information value would be a function only of the object's $I_{1}$, because the $\sin (0)$ eliminates the contribution of

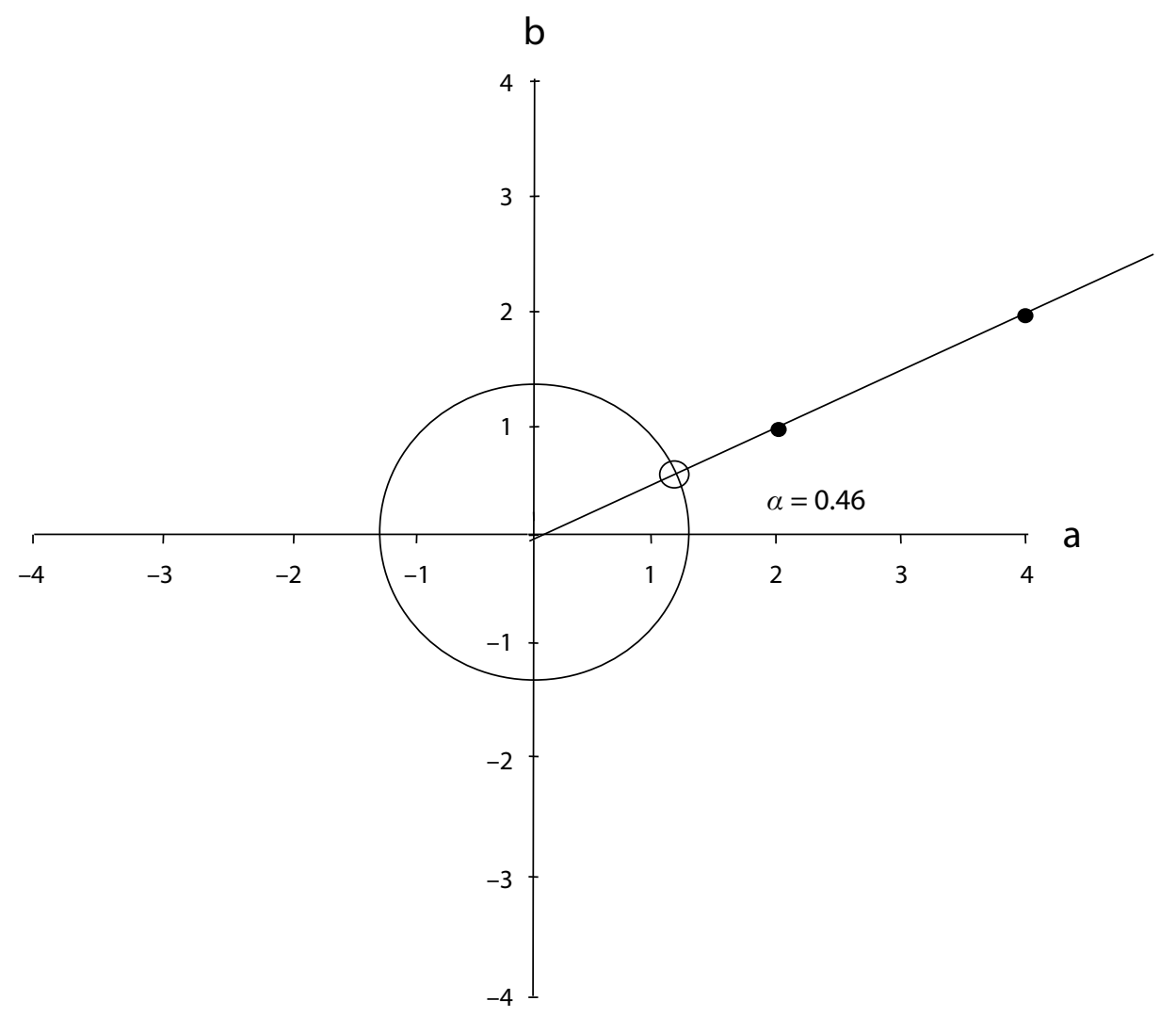

Figure 2. Schematic of the projection of redundant information variables onto a single point on a circle. The line connects all points for which the ratio of the exponent of $I_{1}$ to the exponent of $I_{3}$ is $2: 1$. The point at which this line intersects the circle constitutes the information locus. Loci on the circle are given in angles. The angle for the depicted line is the one whose tangent is $1 / 2$-namely, 0.46 . 
$I_{3}$. At $\alpha=\pi / 2$, the information value for a given object is a function only of $I_{3}$.

The relative usefulness of a given locus for the perceptual task can be measured as the correlation between the information values at that locus and the actual values of the to-be-perceived object property (e.g., length or width). A usefulness function over the space can be calculated by determining these correlations at small increments of $\alpha$. Because different to-be-perceived object properties have different optimal loci, the location of the optimum depends on the property that the participant is to report. For example, the optimum informing about object length is at a locus different from the optimum informing about object width (length and width are the two properties investigated in our experiment). Figure 3 shows the information space for the objects to be used in our experiment, over the range of $-\pi<\alpha<\pi$, with two usefulness curves, one for length and one for width. The peak of each curve represents the optimal locus for perceiving the corresponding object property. To create the curve, $\alpha$ was sampled every $2.2^{\circ}$, yielding 162 sample points.

As noted earlier, the theory of direct learning characterizes learning as movement through the space, and experimental participants given feedback about their performance are expected to move through the space toward the optimum. To determine the locus of a participant on a block of trials, one finds the set of information values (corresponding to a particular locus) correlated most highly with the participant's judgments. Learning, then, is indicated by the participant's succession of occupied loci on the information line over blocks of trials. If given feedback about length, participants should move toward the length optimum. Likewise, if given feedback about width, participants should move toward the width optimum. Although participants might start at different points on the information line, feedback should yield movement in the direction of the optimum. Michaels

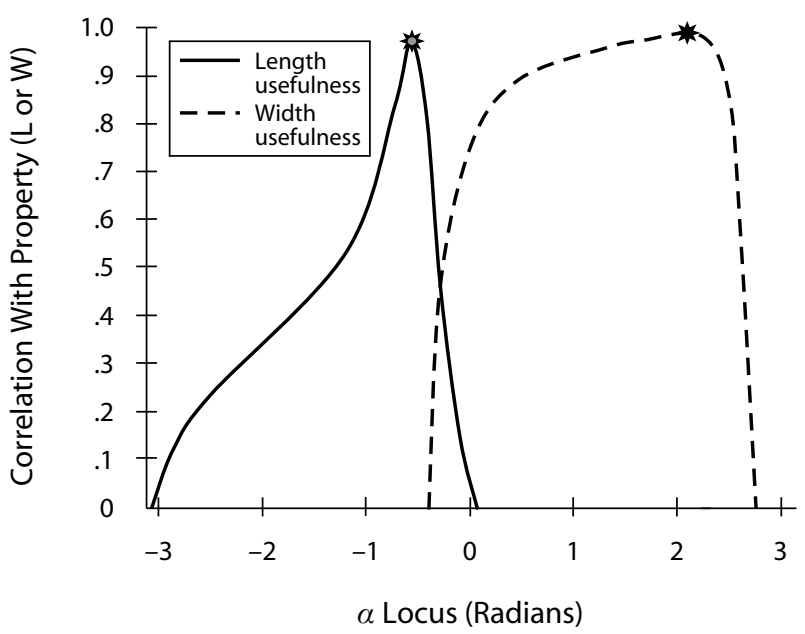

Figure 3. Information line and usefulness curves, given as a function of $\alpha$ (i.e., locus). The $y$-axis represents the correlation between the set of $E_{a}$ values (information values computed using Equation 1) and the set of lengths or widths of the objects. The optima for width and length are indicated by the stars located at the peak of each curve. et al. (2008) reported findings agreeing with this prediction. Participants were provided feedback about the accuracy of their judgments of the lengths of objects. During the first stage of their Experiment 1, an arbitrary optimal locus for length was defined by the feedback, in order to push participants away from the actual optimum for length. In the second stage, participants were given feedback about the actual optimum for length. In both stages, participants reliably progressed toward the optimum corresponding to the provided feedback.

\section{Intention and Information Space}

What happens to attunement (i.e., the locus one occupies in information space) if a perceiver is asked to report a different property of the same object set? More specifically, would a change of intention from perceiving length to perceiving width (or vice versa) result in a shift of attunement toward the appropriate locus, or would the perceiver persist in their current attunement? According to the view of intention advocated above, experienced perceivers should make such a shift of attunement, one to the ballpark of the optimum of the novel property. Moreover, if the optima for length and width are relatively far apart on information space, the magnitude of the attentional shift that accompanies a change of intention should be larger than an attentional shift due to learning; in other words, the attention shift accompanying a change in intention should be seen as a jump - that is, an extensive attentional shift across the information line.

The expectation of such a jump follows both from the co-specificity hypothesis and from empirical observations regarding the success of naive participants (for a summary, see Carello \& Turvey, 2000). Naive participants are able to produce reliable judgments about various properties of handheld objects without being provided feedback. This implies that such tasks are not completely novel. Past experience on a task or similar tasks should, thereby, determine one's initial locus in information space. It is possible that, because of prior learning, a perceiver might leap directly to an optimal locus in information space. That need not be the case, however-in part, because the optimal locus depends also on the physical characteristics of the to-be-perceived object set. Plumbers and pool players, for example, might differ in the variables to which they attend while plying their trades, because the objects they deal with have different invariant properties. Pool cues differ in length and somewhat in density, but pipes differ in inner and outer diameters, length, and density, just to name a few factors. The similarities among pool cues would mean that many variables might specify length (e.g., mass, individual inertial moments) because they are collinear, which would not be true for pipes. These differences mean that a change in intention will not necessarily land perceivers at the optimum, but perhaps near the optimum.

The prediction that movements along the information line during learning are different from movements following a change of intention raises the question of how attunement is to be understood. A change in attunement might be a focal process with no outward manifestations (besides improved judgments); on the other hand, these attunement 
shifts might reflect a change in the manner of explorationwielding the object in a particular way. The co-specificity hypothesis argues for the latter: Intention, attunement, and exploration are all said to be specific to each other (Riley, Wagman, Santana, Carello, \& Turvey, 2002; Turvey et al., 1990). Indeed, exploratory wielding movements have been shown to differ systematically, depending on the intention dictated by the experimenter (Michaels, Weier, \& Harrison, 2007; Riley et al., 2002). Thus, we expected participants to exhibit movements tailored to reveal information about the property they intended to perceive. Particular movements (e.g., twisting, swinging, etc.) might more effectively exploit (or even define) specific areas of the information space.

Whereas the concept of information space has analogues in Brunswikian, connectionist, and Bayesian approaches to learning, the expectation of a key role for exploration is a primarily Gibsonian proposition (but see Drewing \& Ernst, 2006; Lederman \& Klatzky, 1990). That manner of exploration is seen as a selector of information suggests that exploration might be the vehicle of change in perceptual learning, at least in a task such as dynamic touch.

To summarize, perceivers were asked to report some property of an unseen, wielded object, and were given feedback about their accuracy. In a later block of trials, they were asked to report a different property. Over blocks, we tracked their locus on an information manifold. We compared the attentional shifts associated with learning with those associated with intention switching. Furthermore, we asked whether intention would be reflected in the nature of exploratory movements.

\section{METHOD}

\section{Participants}

Twenty male students from the University of Connecticut participated in the study for partial credit in an introductory psychology course. Participants ranged in age from 18 to 24 years. All were right-handed and without motor impairments.

\section{Apparatus}

The experimental setup is depicted in Figure 4. A chair with a right-side armrest was next to an opaque screen hanging from the ceiling. The proximal end of the screen was flush with the participant's right shoulder, concealing the right arm.

The object set consisted of 25 wooden parallelepipeds (see Table 1). The handles attached to the base of each object were 12.5 -cm-long wooden dowels with a $1.8-\mathrm{cm}$ diameter and a mass of $13.4 \mathrm{~g}$. There were approximately $5 \mathrm{~cm}$ between the participant's hand and the base of the parallelepiped.

\section{Design}

Participants were asked to wield the set of unseen parallelepipeds. A five-block, pretest-feedback -feedback $_{2}$-posttest-novel test design was used. We randomly assigned participants into two conditions, the length-then-width condition $(\mathrm{L} \rightarrow \mathrm{W})$ and the width-then-length condition $(\mathrm{W} \rightarrow \mathrm{L})$. In the first four blocks of the $\mathrm{L} \rightarrow \mathrm{W}$ condition, participants indicated the length of the object and received feedback in Blocks 2 and 3, the feedback blocks. Block 4 served as the posttest for the learning phase; no feedback was provided. In the fifth block- the novel test - participants were asked to switch their report to the other object property, width. In the $\mathrm{W} \rightarrow \mathrm{L}$ condition, participants reported width on Blocks 1-4 and length on the novel test, Block 5.5

\section{Procedure}

Participants were initially shown an example object (not part of the actual test set) and were informed that all objects were attached to

Table 1

Object Set Characteristics

\begin{tabular}{|c|c|c|c|c|c|c|c|}
\hline Object & Length $(\mathrm{cm})$ & Width $(\mathrm{cm})$ & Mass (g) & $I_{1}\left(\mathrm{~g} \cdot \mathrm{cm}^{2}\right)$ & $I_{3}\left(\mathrm{~g} \cdot \mathrm{cm}^{2}\right)$ & $\begin{array}{l}\text { Info Values at Length } \\
\text { Optimum }(\alpha=-0.53)\end{array}$ & $\begin{array}{l}\text { Info Values at Width } \\
\text { Optimum }(\alpha=2.09)\end{array}$ \\
\hline 1 & 3.7 & 22.7 & 1,184 & 241,831 & 86,715 & 4.95 & 3.72 \\
\hline 2 & 7.5 & 14.0 & 747 & 160,783 & 22,864 & 5.27 & 2.77 \\
\hline 3 & 7.6 & 18.2 & 1,267 & 291,053 & 64,114 & 5.26 & 3.37 \\
\hline 4 & 7.7 & 17.3 & 880 & 200,634 & 40,473 & 5.17 & 3.15 \\
\hline 5 & 7.9 & 22.8 & 2,400 & 606,830 & 188,158 & 5.35 & 3.94 \\
\hline 6 & 9.6 & 11.1 & 496 & 117,768 & 10,057 & 5.42 & 2.21 \\
\hline 7 & 10.1 & 10.1 & 410 & 99,739 & 7,054 & 5.45 & 1.98 \\
\hline 8 & 10.2 & 21.0 & 1,746 & 483,439 & 119,677 & 5.38 & 3.66 \\
\hline 9 & 10.7 & 8.7 & 434 & 109,160 & 5,846 & 5.62 & 1.77 \\
\hline 10 & 11.4 & 13.9 & 1,162 & 315,594 & 36,612 & 5.61 & 2.84 \\
\hline 11 & 11.7 & 12.6 & 710 & 193,885 & 18,660 & 5.53 & 2.50 \\
\hline 12 & 12.3 & 3.8 & 94 & 26,450 & 512 & 5.63 & 0.36 \\
\hline 13 & 12.7 & 13.8 & 959 & 280,454 & 30,168 & 5.61 & 2.73 \\
\hline 14 & 12.9 & 2.6 & 95 & 27,618 & 405 & 5.79 & 0.14 \\
\hline 15 & 15.2 & 3.8 & 118 & 38,879 & 627 & 5.86 & 0.35 \\
\hline 16 & 16.5 & 16.5 & 1,730 & 637,924 & 78,517 & 5.83 & 3.15 \\
\hline 17 & 17.8 & 2.6 & 118 & 44,679 & 504 & 6.09 & 0.09 \\
\hline 18 & 18.1 & 7.6 & 401 & 153,944 & 4,766 & 6.02 & 1.43 \\
\hline 19 & 19.0 & 11.5 & 1,728 & 705,948 & 41,212 & 6.25 & 2.54 \\
\hline 20 & 21.7 & 8.7 & 889 & 412,488 & 13,591 & 6.34 & 1.85 \\
\hline 21 & 23.2 & 3.8 & 174 & 86,181 & 1,002 & 6.31 & 0.36 \\
\hline 22 & 24.9 & 2.6 & 156 & 83,586 & 729 & 6.45 & 0.10 \\
\hline 23 & 27.9 & 12.7 & 1,649 & $1,034,139$ & 49,426 & 6.49 & 2.51 \\
\hline 24 & 28.5 & 8.7 & 1,186 & 754,597 & 19,168 & 6.69 & 1.85 \\
\hline 25 & 28.9 & 3.8 & 201 & 128,745 & 1,249 & 6.55 & 0.35 \\
\hline
\end{tabular}

Note-Width refers to the square base of the parallelepiped. $I_{1}$ and $I_{3}$ were measured about the wrist. Because the objects have a square cross-section, $I_{1}$ and $I_{2}$ are essentially equal. The two rightmost columns are the information values for length and width at their optima ( $\alpha=-0.53$ and 2.09, respectively), computed from Equation 1 . 


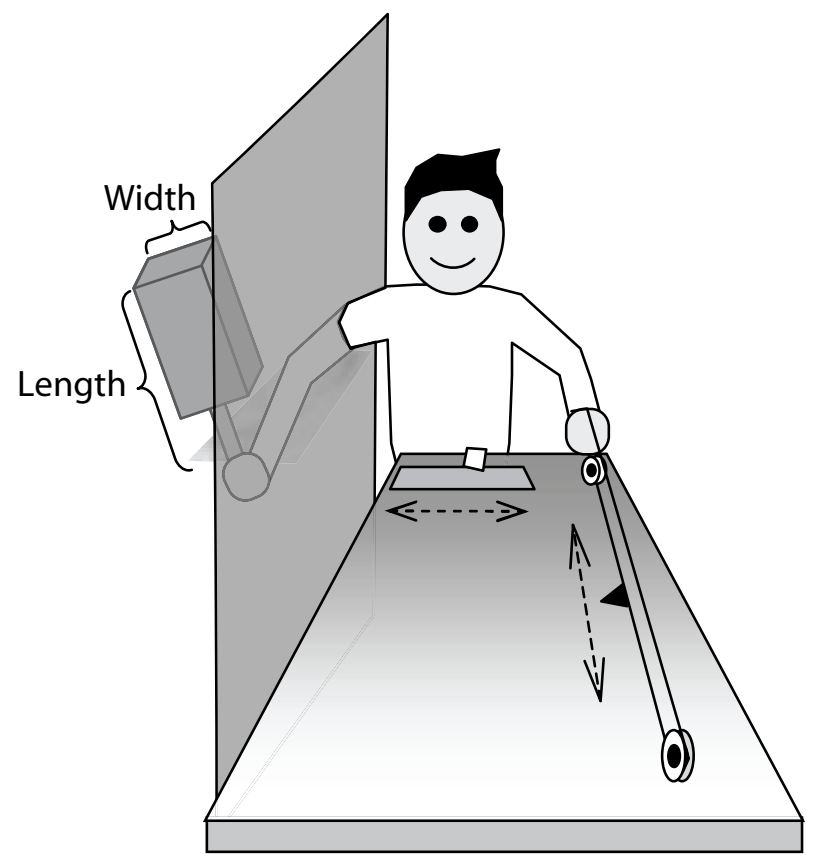

Figure 4. Experimental apparatus. Note that the screen occludes the participant's view of the wielded object. Participants move the width marker laterally when making width judgments. Length judgments are made by pulling on the rope to make the length indicator move forward or backward.

a uniform handle. They were informed that "length" was the extent to which the held object protruded above the hand, whereas "width" was the extent of the object from one side of the grasping hand to the other. They were told that the experiment consisted of five blocks, each composed of 25 trials, and that each object would be presented once per block.

At the outset, participants were told that they would be judging length (or width) for the first four blocks and that feedback would be given during the second and third blocks. On the fifth block, participants were told to report the novel property, width (or length). The length and width indicators were located on a table in front of the participant, as shown in Figure 4. Length judgments were made by manipulating a rope and pulley system that moved a marker forward and backward in a parasagittal plane. The marker was reset to $0 \mathrm{~cm}$ before each trial. Participants were told to move the marker to the location of the distal end of the object, were it held parallel to the table. Width judgments were made by moving a marker on a metal slider that was in a frontoparallel plane. For width judgments, participants were told to position the marker so that the object would fit exactly between the marker and the screen, which was flush with the right side of the table. Each object was held so that the bottom of the hand was flush with the bottom of the handle. Participants were told to keep their right forearms flat on the armrest during wielding and to keep a firm grip on the object. The left hand was used to move the pulley system's rope (for length judgments) or the metal slider (for width judgments).

Movements were tracked on all trials for the final 3 participants in each condition. A marker was placed on the bottom of the object's handle before each trial. Movement data were collected using a magnetic tracking system (Polhemus Fastrak, Polhemus Corporation, Colchester, VT) and 6-D research system software (Skill Technologies, Inc., Phoenix, AZ). Movements were recorded at $120 \mathrm{~Hz}$ from the time the object was handed to the participant until the response was made.

Two experimenters were present. One experimenter remained behind the curtain and handed the objects to the participant. A second experimenter sat on the participant's left, provided feedback, and operated the movement-tracking software. After the participant registered his or her response, the experimenter provided feedback (in Blocks 2 and 3 ) by adjusting the measurement apparatus to the correct length or width for the given object. The entire experiment lasted 70-90 min, including a mandatory 5-min break taken after the third block.

\section{RESULTS AND DISCUSSION}

We divide our results into two sections. In the first, we present the effects of feedback and intention switching on performance and attunement. The second section covers their effects on the exploratory movements.

\section{Performance and Attunement}

Before addressing our main findings on the effects of intention on attunement, we examine the trends in performance. We quantified performance within each block by calculating the Pearson product-moment correlation between judgments and actual lengths or actual widths for each participant. We used correlations, rather than absolute accuracy of judgments, because the latter depends on both attunement and calibration, and our interest is only in attunement. ${ }^{6}$ The results are plotted in the upper panel of Figure 5. We first tested whether feedback improved performance by using a 2 (condition: $\mathrm{L} \rightarrow \mathrm{W}$ vs. $\mathrm{W} \rightarrow \mathrm{L}$ ) $\times 4$ (block: the learning phase, pretest-

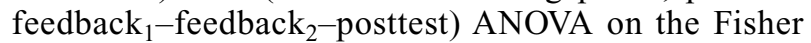
$z$ transformations of the correlations between judgments and actual length or width. The correlations increased after the participants were given feedback, as indicated by a significant main effect of block $[F(3,54)=11.65$, $\left.p<.001, \eta_{\mathrm{p}}^{2}=.393\right]$. A significant main effect of condition $\left[F(1,54)=42.17, p<.001, \eta_{\mathrm{p}}^{2}=.438\right]$ revealed that the $\mathrm{W} \rightarrow \mathrm{L}$ group performed better than the $\mathrm{L} \rightarrow \mathrm{W}$ group; that is, width judgments were more highly correlated with width than length judgments were correlated with length. There was no significant condition $\times$ block interaction.

To test whether the switch in intention affected performance, we used a 2 (condition: $\mathrm{L} \rightarrow \mathrm{W}$ vs. $\mathrm{W} \rightarrow \mathrm{L}$ ) $\times$ 2 (block: posttest vs. novel test) ANOVA. The main effect of condition was not significant. There was a nonsignificant trend of block $\left[F(1,18)=3.82, p=.067, \eta_{\mathrm{p}}^{2}=.175\right]$, but the block $\times$ condition interaction was significant $\left[F(1,18)=70.0, p<.001, \eta_{\mathrm{p}}^{2}=.800\right]$ (see Figure 5, top, Blocks 4 and 5). Between Blocks 4 and 5, the $\mathrm{L} \rightarrow \mathrm{W}$ group improved from $r=.563$ to .789 , whereas the $\mathrm{W} \rightarrow \mathrm{L}$ group worsened from $r=.846$ to .437 , which was consistent with the main effect of condition reported in the previous ANOVA. Tukey's post hoc analyses were used to compare Block 4 with Block 5 performance and were significant $(p<.01)$ for both conditions: Performance improved for the $\mathrm{L} \rightarrow \mathrm{W}$ group and got worse for the $\mathrm{W} \rightarrow \mathrm{L}$ group.

Both ANOVAs reveal that the length-judgment task was more challenging than was the width-judgment task. The relative difficulty of length perception could be due to the fact that the range of information values for width is larger than the range of information values for length (see, e.g., the two rightmost columns in Table 1). This more extensive range of useful information may have made discrimi- 

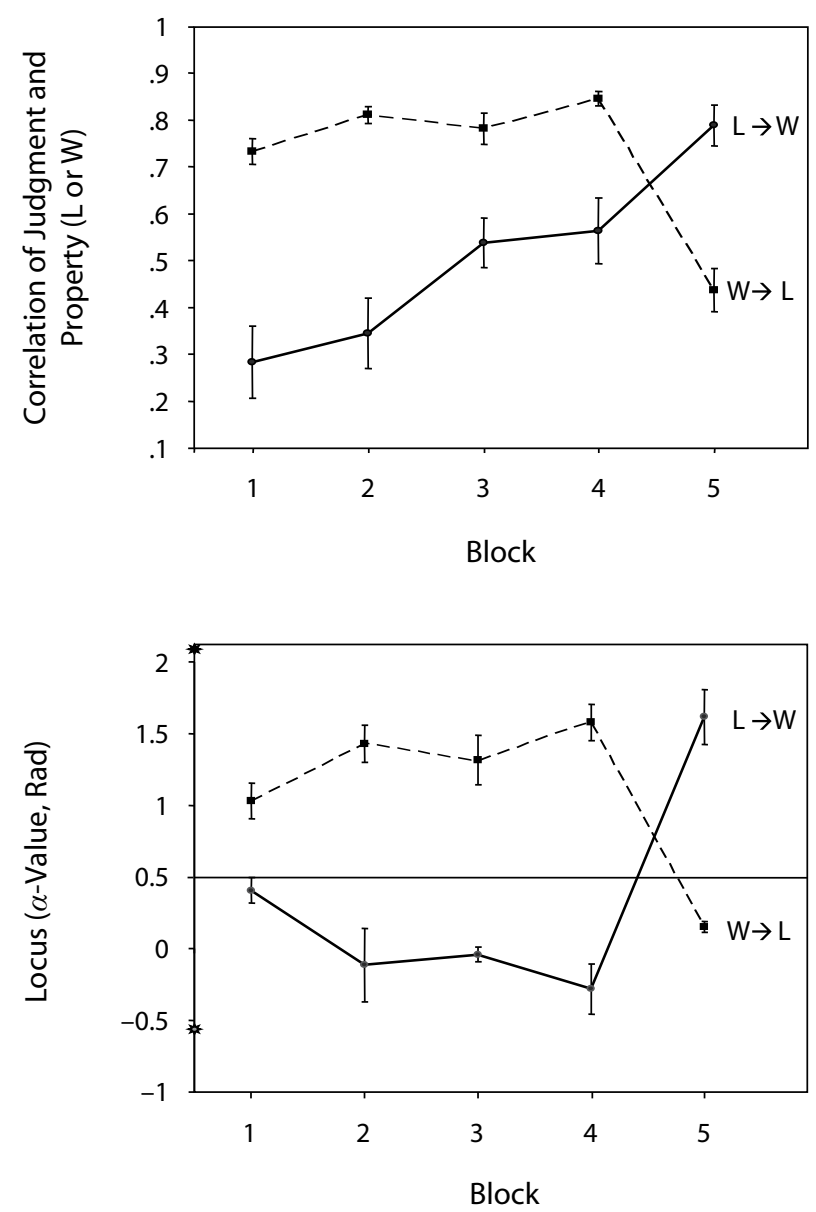

Figure 5. Average performance (top) and attended loci (bottom) plotted as a function of blocks and conditions. Error bars indicate the standard error over 10 participants. The stars on the ordinate of the bottom graph indicate the optima.

nations among stimuli easier for the width task. In any event, length judgments are not inherently more difficult than width judgments. In fact, Riley et al. (2002) demonstrated a length-over-width superiority, further implying that our effect is a consequence of characteristics of the object set.

We now turn to our main concern, the effects of learning and intention on attunement - that is, on participants' movements in information space. We determined a participant's attended-to locus for each block by first computing the correlations between judgments and the set of information values (from Equation 1) corresponding to each of the 162 loci from $\alpha=-\pi$ to $\alpha=\pi$ (i.e., those used to create Figure 3). Next, we selected the highest of these correlations, which we deemed the participant's operative $\alpha$-locus for that block. The peak correlations averaged over participants and blocks was .745. The $\alpha$ values were used in the ANOVAs described in the following three paragraphs. The averages of these attended loci (over participants) are presented in the bottom panel of Figure 5. ${ }^{7}$

Regarding feedback about the to-be-reported property, we expected that participants would attend to variables successively closer to the optimum. We conducted a condition $\times$ block ANOVA on the first four blocks (i.e., the learning phase) to analyze the effect of learning on attunement. The main effect of condition was significant $\left[F(1,18)=88.65, p<.001, \eta_{\mathrm{p}}^{2}=.831\right]$; attunement depended on the to-be-perceived property. In Figure 5, we can see that participants in the $\mathrm{W} \rightarrow \mathrm{L}$ condition exploited regions of the information line where $\alpha$ was positive, whereas participants in the $\mathrm{L} \rightarrow \mathrm{W}$ condition exploited regions where $\alpha$ was negative. A significant interaction $\left[F(3,54)=8.08, p<.001, \eta_{\mathrm{p}}^{2}=.310\right]$ showed that over blocks, the $\mathrm{L} \rightarrow \mathrm{W}$ and $\mathrm{W} \rightarrow \mathrm{L}$ groups moved in opposite directions on the information line. On average, participants in the $\mathrm{L} \rightarrow \mathrm{W}$ condition started in a negative region on the information line and moved in a negative direction over blocks toward the optimum for length at $\alpha=-0.53$. Participants in the $\mathrm{W} \rightarrow \mathrm{L}$ condition, on the other hand, started in a positive region on the information line and moved in a positive direction over blocks toward the optimum for width at $\alpha=2.09$. Because participants moved in opposite directions in the two conditions, there was no main effect of block $[F(3,54)=1.12, p>$.1]. Table 2 presents the loci for individual participants.

To test whether the change of intention affected attunement, we compared loci using a 2 (condition) $\times 2$ (block: posttest vs. novel test) ANOVA. The interaction was significant $\left[F(1,18)=164.56, p<.001, \eta_{\mathrm{p}}^{2}=.901\right]$; the intention switch induced a large jump across the information space for both conditions (see Figure 5, bottom, Blocks 4 and 5). Both groups jumped into the ballpark of the information for the novel to-be-perceived property. In the $\mathrm{L} \rightarrow \mathrm{W}$ condition, all participants jumped to a positive locus in Block 5; in the $\mathrm{W} \rightarrow \mathrm{L}$ condition, all participants jumped to a negative locus (see Table 2). The main effects were not significant.

Table 2

Locus per Block for Each Participant in Each Condition

\begin{tabular}{rrrrrr}
\hline Participant & Pretest & Feedback 1 & Feedback 2 & Posttest & $\begin{array}{c}\text { Novel } \\
\text { Test }\end{array}$ \\
\hline \multicolumn{5}{c}{$\mathrm{L} \rightarrow \mathrm{W}$} \\
1 & -0.37 & -0.41 & -0.41 & -0.45 & 1.15 \\
2 & -0.29 & -0.25 & -0.45 & -0.60 & 1.93 \\
3 & -0.25 & -0.25 & -0.45 & -0.53 & 1.62 \\
4 & -0.14 & -1.11 & -0.84 & -0.72 & 0.37 \\
5 & 0.06 & -2.75 & -0.84 & -0.88 & 0.25 \\
6 & -0.41 & -0.45 & -0.41 & -0.64 & 1.07 \\
7 & 0.49 & -0.45 & -0.60 & -0.80 & 0.49 \\
8 & 0.21 & 0.02 & -0.45 & -2.32 & 1.00 \\
9 & -0.25 & -0.10 & -0.49 & -0.45 & 1.39 \\
10 & 0.02 & -0.37 & -0.45 & -0.49 & 1.89 \\
& & $\mathrm{~W} \rightarrow \mathrm{L}$ & & & \\
1 & 0.33 & 1.03 & 1.50 & 1.03 & -0.49 \\
2 & 1.50 & 1.85 & 2.01 & 1.93 & -0.33 \\
3 & 0.10 & 0.72 & 0.60 & 0.84 & -0.45 \\
4 & 0.45 & 1.11 & 0.53 & 0.88 & -0.33 \\
5 & 0.33 & 0.88 & 0.33 & 0.92 & -0.25 \\
6 & 0.60 & 0.57 & 0.57 & 1.27 & -0.49 \\
7 & 0.29 & 1.19 & 0.64 & 0.92 & -0.49 \\
8 & 0.49 & 0.88 & 1.07 & 0.96 & -0.18 \\
9 & 0.80 & 0.57 & 0.57 & 1.50 & -0.25 \\
10 & 0.41 & 0.49 & 0.33 & 0.53 & -0.21 \\
& & & & &
\end{tabular}


To establish the difference between learning and intention, we further compared the average magnitude of the movements made on the information line during the learning phase (i.e., Blocks 1 to 2, Blocks 2 to 3 , and Blocks 3 to 4) with the magnitude of movements made during the intention switch (i.e., Blocks 4 to 5). Using a 2 (condition) $\times 2$ (phase: learning phase vs. intention switch) ANOVA, we found that the main effect of phase was significant $\left[F(1,18)=149.85, p<.001, \eta_{\mathrm{p}}^{2}=.893\right]$; participants moved farther on the information line for an intention switch than they moved during learning (see Figure 6). There was no significant effect of condition and no significant interaction.

To conclude our analysis of performance and attunement, we illustrate some movements made by 1 average and 1 exceptional participant from each condition. Figure 7 presents a magnified section of the information line previously depicted in Figure 3, the section that participants reliably populated. The top two panels are participants from the $\mathrm{L} \rightarrow \mathrm{W}$ condition. Consistent with the ANOVAs already presented, both participants showed an overall improvement in performance (i.e., height on the $y$-axis) as a function of feedback about length in Blocks 2 and 3. Both participants also gradually moved across the information line over the first four blocks, finally ending near, or on, the optimum for length at $\alpha=-0.53$. With the intention switch between Blocks 4 and 5, Participant $\mathrm{L} \rightarrow \mathrm{W} 2$ (top left) jumped across the information line, landing directly on the optimum for width. Such precise attunement was not the norm (see Table 2). Participant $\mathrm{L} \rightarrow \mathrm{W} 3$ (top right) better typifies the intentional jump for the $\mathrm{L} \rightarrow \mathrm{W}$ condition; he lands to the left of, but not on, the optimum for width. Analogous trends in performance and attunement are demonstrated by the $2 \mathrm{~W} \rightarrow \mathrm{L}$ participants (bottom).

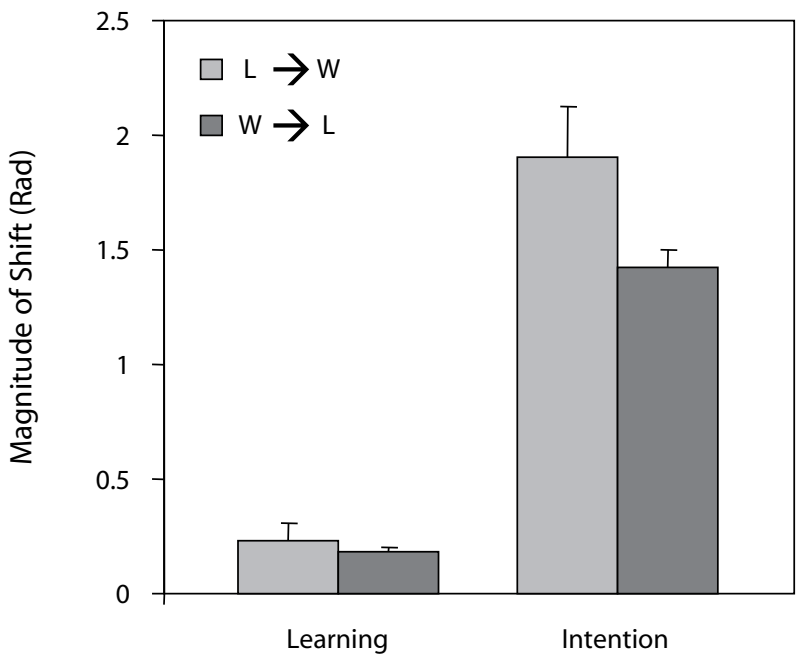

Phase

Figure 6. Mean magnitudes of attention shifts along the information line given as a function of condition and phase (learning across Blocks 1-4 and intention switch across Blocks 4 and 5). Error bars indicate the standard error of the mean shift magnitudes for the 10 participants in each condition.
Like the two $\mathrm{L} \rightarrow \mathrm{W}$ examples just described, both $\mathrm{W} \rightarrow \mathrm{L}$ participants show an overall improvement in performance during the learning phase. With regard to attunement, Participant $\mathrm{W} \rightarrow \mathrm{L} 2$ (bottom right) started relatively close to the optimum in his pretest $(\alpha=1.50)$. Because of his initial proximity to the optimum, there is very little movement on the information line during the learning phase, followed by a large jump between Blocks 4 and 5. Participant $\mathrm{W} \rightarrow \mathrm{L} 1$ (bottom left), on the other hand, was very far from the optimum in the pretest $(\alpha=0.33)$. After feedback in Blocks 2 and 3 , he moved across a large section of the information line. In Block 4, he reversed direction toward the variable originally exploited in the pretest. Such reversals were seen more often in the $\mathrm{W} \rightarrow \mathrm{L}$ condition. Perhaps this finding can be ascribed to the shape of the usefulness curve for width; its wider range might allow for more successful width judgments, as compared with the relatively small range for length. It is also possible that measurement error contributes to apparent changes in loci in this region. Just as the similar values in this region all correlate highly with actual width, they also correlate highly with participants' judgments of width, making it more difficult to determine a participant's exploited locus with precision.

\section{Analyses of Exploratory Movements}

Our movement analyses concentrated primarily on spatial aspects of movement, identifying the axes on which the parallelepiped was rotated. ${ }^{8}$ Preliminary analyses of the wielding movements suggested that exploration on any trial comprised one or more bouts of different movements, rather than a single discrete or repetitive movement of one type or another. Two of the authors divided each trial into such bouts as follows: The time series of the three object orientations, anterior-posterior, left-right, and twist (see Figure 8) were plotted using MATLAB, and the beginning and ending of each apparent bout were marked and recorded. Three examples of exploratory movement data are presented and described in the Appendix, together with the identified segmentations into bouts. Several dependent measures were calculated for each bout: the maximal excursion on each axis, the correlations between all pairs of angles (to distinguish circular vs. linear movements), and spectral analysis (yielding peak frequency and power) on each angle. From these bout data, the trial as a whole was categorized as to whether at least one bout contained the following components: (1) anterior-posterior (AP) rotations, (2) left-right (LR) rotations, or (3) twists along the parallelepiped's longitudinal axes; (4) circular movements; and (5) oscillation (vs. discrete movements) in any direction. To be counted, rotations needed to be greater than 1 radian, and oscillations needed to contain a peak in the power spectrum greater than $0.1 \mathrm{~Hz}$. Although the segmentations were somewhat different between the two raters, the final classifications of each trial were in substantial agreement; of the 750 exploration trials from 6 participants, the classifications agreed on $97 \%, 82 \%$, $94 \%, 84 \%$, and $76 \%$ of the trials for twist, AP, LR, circular, and oscillatory categories, respectively.

Additional dependent measures were computed for the entire trial (i.e., ignoring segments): the duration of ex- 

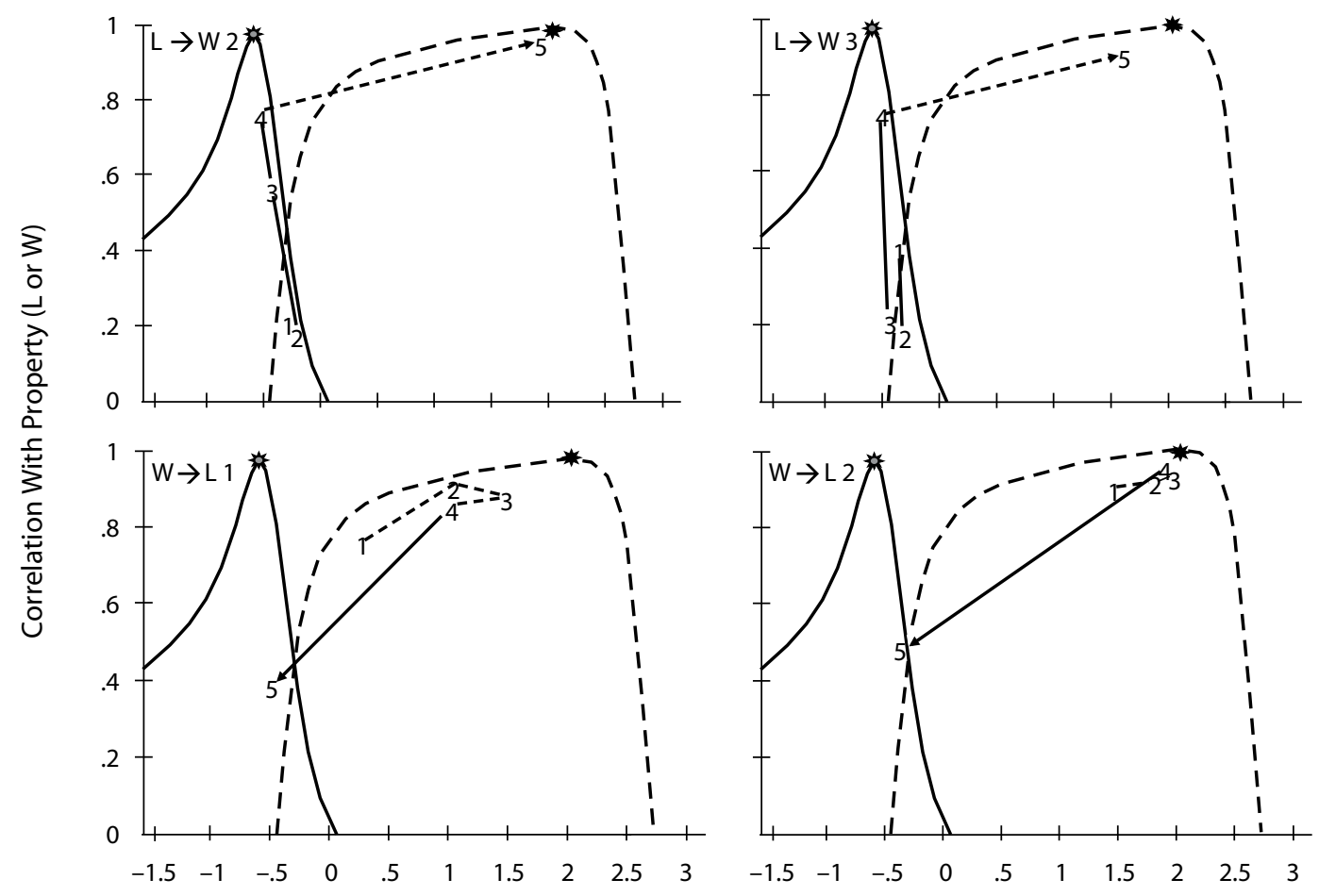

$\alpha$ Locus (Rad)

Figure 7. Observed loci and performance of 4 participants. The solid curve depicts the usefulness for length, and the dashed curve, width. Numerals indicate block numbers. Their horizontal positions indicate the attended-to locus; the vertical position indicates performance. Each of the top panels depicts learning and intention jumps for a participant in the $L \rightarrow W$ condition. Each of the bottom panels shows movements in the $W \rightarrow L$ condition.

ploration and, to test complexity of movement, a principal components analysis (PCA) of all 12 channels of the Polhemus output (nine direction cosines, capturing three angles, and three spatial coordinates). Measures of complexity based on the PCA were (1) the number of principal components needed to account for $90 \%$ of the variance in each trial and (2) the algorithmic complexity of the first principal component - roughly, how many program lines would be needed to generate the pattern (Lempel \& Ziv, 1976). The whole-trial analyses address how extensive and complex the exploration was; the bout analyses address the character of the movements. We begin with the measures concerning the entire trial.

A condition $(\mathrm{L} \rightarrow \mathrm{W}$ vs. $\mathrm{W} \rightarrow \mathrm{L}) \times$ block ANOVA on per-trial average duration of exploration revealed that all three effects were significant. The main effect of blocks was that exploration was longer in the feedback blocks than in the test blocks $\left[F(4,16)=12.65, p<.001, \eta_{\mathrm{p}}^{2}=\right.$ $.760]$. The anticipation of feedback seemed to motivate participants to explore more thoroughly. The main effect of condition was that wielding duration was considerably longer in the $\mathrm{L} \rightarrow \mathrm{W}$ condition $(M=10.24 \mathrm{sec})$ than in the $\mathrm{W} \rightarrow \mathrm{L}$ condition $(M=3.84 \mathrm{sec})[F(1,4)=32.51$, $\left.p=.005, \eta_{\mathrm{p}}^{2}=.890\right]$. The condition difference also varied with block $\left[F(4,16)=9.26, p<.001, \eta_{\mathrm{p}}^{2}=.698\right]$, as plotted in Figure 9. The difference in exploration times suggests that perceiving length was more difficult than perceiving width, consistent with performance measures depicted in Figure 5. It is interesting, however, that the two conditions did not differ on the Block 5 novel tests and that they were among the briefest explorations. Together, these results suggest that extended exploration seems to happen in the context of making the more difficult length discriminations, but only when feedback is expected. Analogous results with the same significances were found with another dependent variable, the number of identified bouts; the maximum number of bouts $(M=3.1)$ occurred in Block 2 of the $\mathrm{L} \rightarrow \mathrm{W}$ group, and the minimum numbers on Blocks 1 and 5 ( $M=1.3$ and 1.1, respectively) occurred in the $\mathrm{W} \rightarrow \mathrm{L}$ group.

As to our complexity measures, an ANOVA revealed that the number of principal components did not differ among blocks and conditions. Algorithmic complexity, however, was higher for the $\mathrm{W} \rightarrow \mathrm{L}$ condition $(M=0.310)$ than for the $\mathrm{L} \rightarrow \mathrm{W}$ condition $(M=0.216)[F(1,4)=21.65, p<.01$, $\left.\eta_{\mathrm{p}}^{2}=.844\right]$. The block $\times$ condition interaction $[F(4,16)=$ $\left.11.167, p<.001, \eta_{\mathrm{p}}^{2}=.737\right]$ was due to the crossover between Blocks 4 and 5 (i.e., the intention switch) for the two conditions. In condition $\mathrm{L} \rightarrow \mathrm{W}$, exploration became more complex during Block 5 when participants were making width judgments; in condition $\mathrm{W} \rightarrow \mathrm{L}$, movements became less complex following the intention switch to length. Both the main effect and interaction, then, are due to greater complexity of wielding in the width-determination task. 


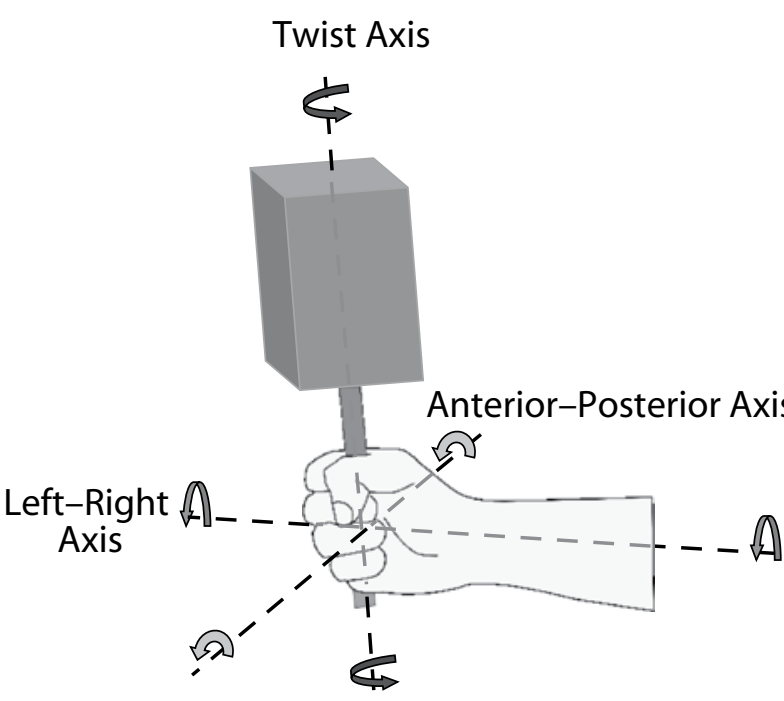

Figure 8. Identification of the rotation directions for the analysis of exploratory movements. The movement marker was attached to the bottom of the object's handle. The actual axis of twist rotations was about the wrist.

To test whether the qualitative aspects of the exploratory movements differed for the two tasks, and whether they changed over the course of the experiment, we tracked the frequency of trials exhibiting each of the five movement categories (AP, LR, circular, twists, and oscillation) over blocks and conditions. A chi-square test on frequencies of trials with AP rotations, summed over participants, showed different patterns between the two conditions, as shown in Figure $10\left[\chi^{2}(4)=25.63, p<.001\right]$. Similarly, twisting movements showed different patterns $\left[\chi^{2}(4)=9.49, p=.05\right]$. The figure shows more twisting in the learning phase of the $\mathrm{W} \rightarrow \mathrm{L}$ condition and more AP movements in the learning phase of the $\mathrm{L} \rightarrow \mathrm{W}$ condition. This suggests that AP movements were likely used to

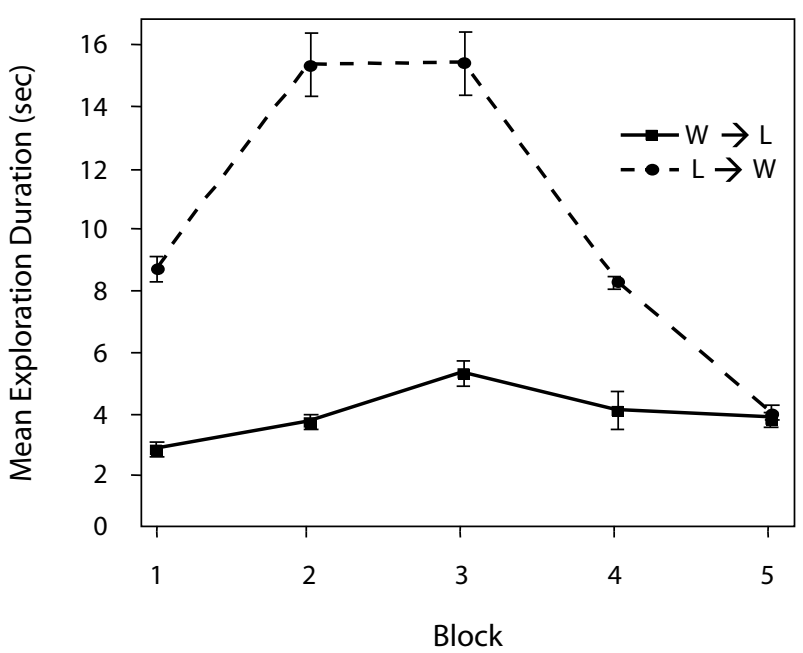

Figure 9. Duration of exploration plotted as a function of condition and block. Each condition depicts the means for 10 participants.
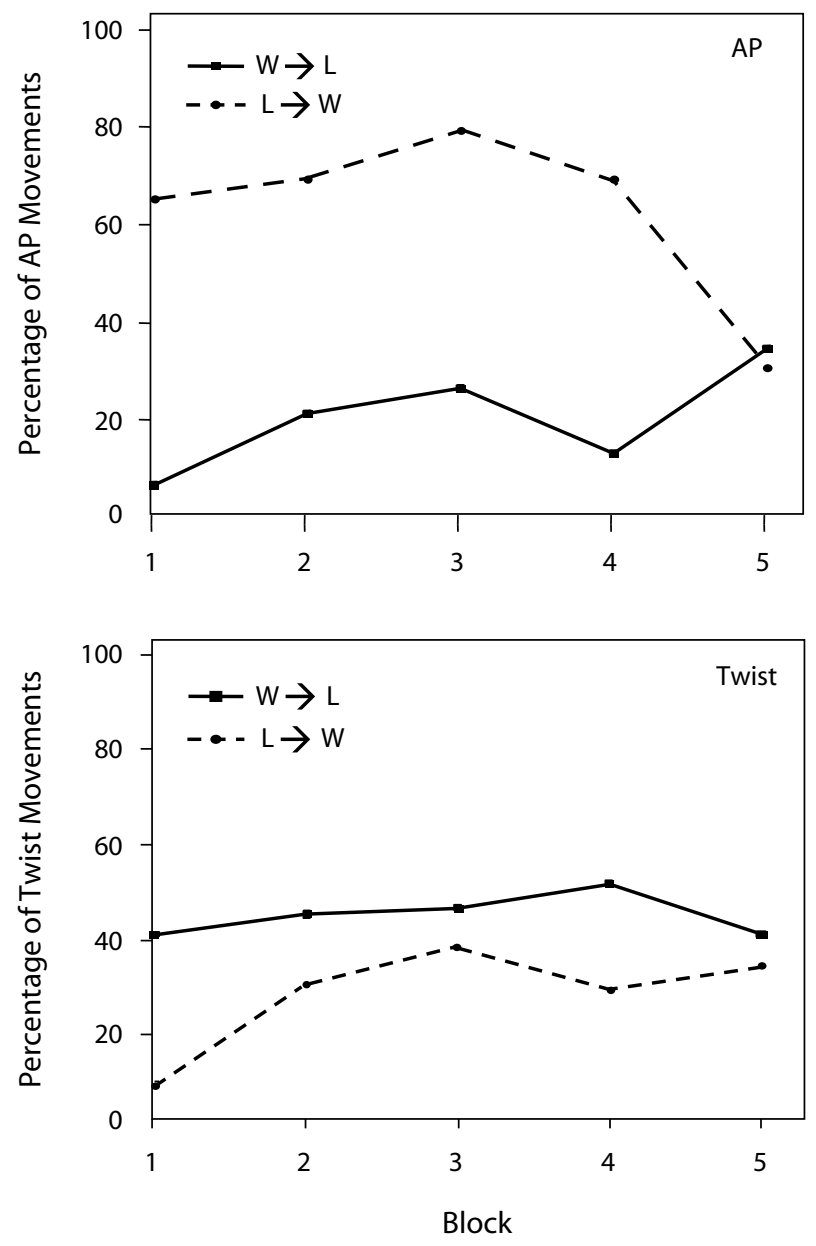

Figure 10. Percentages of the total 75 trials (over 3 participants) exhibiting anterior-posterior (AP) rotations (above) or twists (below), by condition and block.

reveal information useful for perceiving length, whereas twisting movements were more likely used to reveal information useful for perceiving width. It is interesting to note that a substantial shift on the novel test (i.e., Block 5) was seen only for AP movements. Later, we tried to rationalize these differences. Circular movements and oscillation, both of which occurred on about half the trials, did not show significantly different patterns for the two conditions. Of the LR rotations, 47 of the 55 observed trials with rotations were made by a single participant, so these were not analyzed.

The difference in exploration style in the two conditions makes it interesting to ask whether utilization of some particular locus on the information line can be identified with a particular exploratory movement or collection of movements. We examined the frequency of each of four exploratory movement directions as a function of the locus occupied by that participant on that block of trials; these are presented in Figure 11. Note, first, that the AP and LR rotations display a similar pattern, with both movements being more frequent for loci with negative $\alpha$ s. The symmetry of the stimuli makes these movements (and 


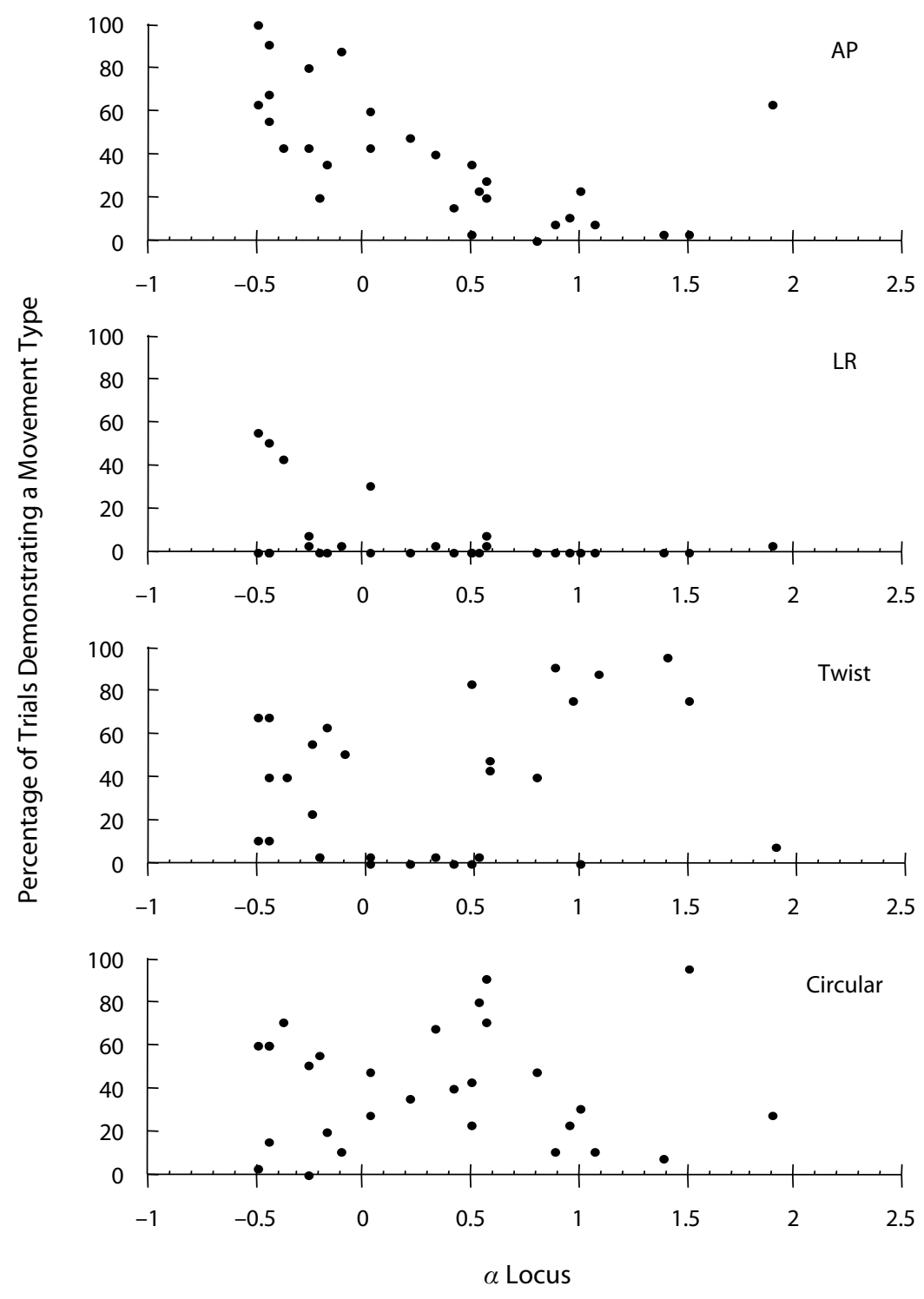

Figure 11. Each point represents a block of 25 trials. The horizontal position of the point represents where the learner was in information space, as given in Table 2 . The vertical position is the percentage of that block's 25 trials on which the movement type was seen. An additional point at $\alpha=-2.75$ (see Table 2) was omitted to help make the pattern of the other points more visible. The movement types from top to bottom are anterior-posterior (AP), left-right (LR), twisting, and circular movements.

movements on any AP/LR diagonal) similar in terms of revealing inertial properties. Twisting movements and circular movements also share a similar pattern. Each type is frequent with both negative and positive $\alpha$ loci, the negative range associated with length judgments and the positive range with width judgments.

To summarize, aspects of the observed exploratory movements differed in the two conditions and over blocks of trials. Most important, the pattern of movements differed as a function of locus in the information space. This leads to the tantalizing conclusion that learning to exploit a particular region of the information space may entail learning to manipulate the object in a particular way.

\section{CONCLUSION}

A comprehensive theory of attention to information variables cannot focus solely on the learning process. Intention, which selects the environmental property to be perceived, is also implicated. Although experience presumably educates intention as well as attention (Jacobs \& Michaels, 2002), our concern here has been with characterizing how a switch in intention manifests itself. We have done this in the context of intention's hypothesized entailments of exploratory style and to-be-exploited information (i.e., the co-specificity hypothesis articulated by Riley et al., 2002, and Turvey et al., 1990) and the theory of direct learning 
(Jacobs \& Michaels, 2007). The co-specificity hypothesis motivated the questions both of whether an intention entails the pickup of particular information and of whether it does so by engaging particular patterns of exploration. The concept of information space from the theory of direct learning provided a way of measuring how intention affects what information is exploited. In this concluding section, we summarize our findings and discuss our two empirical contributions, those regarding distinct types of change in locus on the information line and those regarding the exploratory movements made during wielding.

A preliminary goal of our experiment was to replicate and extend the findings of Michaels et al. (2008) that perceptual learning in dynamic touch is a process involving gradual shifts in attunement to more useful information. Participants were provided with feedback about length or width in Blocks 2 and 3 of the learning phase (i.e., Blocks 1-4). Feedback led to improved performance over blocks, as well as to gradual movements on the information line - shifts of attunement - in the direction of the optimum. This was seen both in a length-perception task, as had been reported by Michaels et al. (2008), and for the first time in a width-perception task.

We expanded on Michaels et al.'s (2008) experimental methods to investigate how a change of intention might affect attunement. We had expected that shifts of intention would lead to a larger movement on the information line. This expectation was motivated by the co-specificity hypothesis that the intention to perceive some property, together with previous experience relevant to perceiving that property, might well initially direct attention to a variable in the ballpark of the optimum for that property. This second hypothesis was also supported: During the intention switch (i.e., between Blocks 4 and 5), participants made large jumps on the information line, in comparison with the smaller movements associated with learning (see Figure 6). Both the Block 1 attunement and the Block 5 attunement were to the general regions of the respective optima (see Table 2). These initial attunements determine the remaining distance that the perceiver needs to traverse to achieve optimal performance in the task (i.e., learn to attend to the optimal variable).

It is important to note that without an intention, there is no informational optimum. The information landscape is flat; there can be no differences in usefulness if there is no use. An intention (including an experimenter-dictated intention enforced with feedback) deforms the landscape, creating an attractor. For example, the two optima in Figure 3 constitute the two attractors, corresponding to the two intentions. ${ }^{9}$ When an intention is fulfilled or changed, the corresponding attractor dissolves. This phrasing simply puts into the language of abstract attractor dynamics the point made by Jacobs and Michaels (2007) that the very concept of specificity of information entails an agent intent on perceiving some property, and echoes the much earlier postulate of Shaw and McIntyre (1974) on how psychological information depends on the algorist, "that aspect of man, organism or machine that both expends the cost of executing algorithms as well as constrains the selection of processing goals" (p. 321).
As is observed in note 2 , theories that posit cue combination in perception have de facto information spaces, so the predictions summarized and the conclusions drawn thus far in this section should be of interest to advocates of those theories. These predictions and conclusions do not distinguish between direct learning and cue combination. However, the emphasis in direct perception and direct learning on exploration and obtained information involves a pivotal distinction, and motivated a search for differences in exploration.

To determine possible corollaries of the change in loci, both from learning and from intention switching, we tracked the exploratory wielding movements made by 3 participants in each condition. We found that different types of movements were made, depending on a participant's locus on the information line. The movement data demonstrated the expected links between intention, attunement, and specific types of exploratory movements; that is, different intentions yielded different manners of exploration and were associated with different loci on the information line. Intention may be seen as constraining wielding movements so as to permit the efficient extraction of the information about the to-be-perceived property. Intention affected the proportions, types, and complexity of wielding movements. When participants explored with AP rotations alone, for example, they put themselves on the negative side of the information line, where the optimum for length resided.

The co-specificity hypothesis, with its necessary links between intention, exploratory style, and exploited information, illustrates the Gibsonian thesis that organisms act so as to make available the information appropriate for the current task (J. J. Gibson, 1958). Exploratory movements create transformations that reveal invariant structures in those fields. These invariants are specific to properties of the environment. Manipulating an object in a certain manner (e.g., translating it or rotating it about some axis) unveils inertial properties of that object (e.g., mass or moment of inertia) that are lawfully related to tobe-perceived properties. In other words, perceiver-actors transform the sensory array such that relevant invariants are revealed through those transformations. These ideas are also closely allied with Runeson's concept of a smart perceptual device, which is said to directly pick up higher order variables without the registration of lower order variables (Bingham, Schmidt, \& Rosenblum, 1989; Michaels \& Carello, 1981; Runeson, 1977). In this case, registering information entails exploration that capitalizes on law-based regularities (e.g., the relation between applied torques, moments of inertia, and rotational accelerations) or local peculiarities (e.g., idiosyncrasies of the stimulus set). These regularities and peculiarities constrain the relations between detectable information variables and to-beperceived object properties (see also Turvey, 1988).

Exploration in dynamic touch illustrates an important way in which the ecological conceptualization of attention differs from the more passive (i.e., covert) view of attention common in other areas of cognitive science. These include spatial zooming in, or keying in on features or even whole objects. In the ecological view, attention is the control of detection (Michaels \& Carello, 1981) and is 
often underlain by active exploration. Attention as active exploration is the obtaining of information (J. J. Gibson, 1966), and the education of attention (perceptual learning) is the training of exploration. Whether this action-based perceptual learning is a special case or a general principle that could capture much or all of perceptual learning is an issue of considerable interest.

\section{AUTHOR NOTE}

The research reported here was supported by the National Science Foundation under Grant BCS 0339031. Correspondence concerning this article and reprint requests should be addressed to R. Arzamarski, Department of Psychology, U-20, 406 Babbidge Rd., University of Connecticut, Storrs, CT 06269 (e-mail: ryanarz91@gmail.com).

\section{REFERENCES}

Bingham, G. P., Schmidt, R. C., \& Rosenblum, L. D. (1989). Hefting for a maximum distance throw: A smart perceptual mechanism. Journal of Experimental Psychology: Human Perception \& Performance, 15, 507-528. doi:10.1037/0096-1523.15.3.507

Burton, G., Turvey, M. T., \& Solomon, Y. (1990). Can shape be perceived by dynamic touch? Perception \& Psychophysics, 48, 477-487.

Carello, C., Thuot, S., Anderson, K. L., \& Turvey, M. T. (1999). Perceiving the sweet spot. Perception, 28, 307-320. doi:10.1068/ p2716

Carello, C., \& Turvey, M. T. (2000). Rotational dynamics and dynamic touch. In M. Heller (Ed.), Touch, representation and blindness (pp. 27-66). Oxford: Oxford University Press.

Carello, C., \& Turvey, M. T. (2004). Physics and psychology of the muscle sense. Current Directions in Psychological Science, 13, 25-28. doi:10.1111/j.0963-7214.2004.01301007.x

DREWING, K., \& ERNST, M. O. (2006). Integration of force and position cues for shape perception through active touch. Brain Research, 1078, 92-100. doi:10.1016/j.brainres.2005.12.026

Gibson, E. J. (1969). Principles of perceptual learning and development. New York: Appleton-Century-Crofts.

Gibson, J. J. (1958). Visually controlled locomotion and visual orientation in animals. British Journal of Psychology, 49, 182-194.

GiBson, J. J. (1966). The senses considered as perceptual systems. Boston: Houghton Mifflin.

Greene, P. H. (1972). Problems of organization of motor systems. In R. Rosen \& F. M. Snell (Eds.), Progress in theoretical biology (Vol. 2, pp. 303-338). New York: Academic Press.

IBERALL, A. S. (1977). A field and circuit thermodynamics for integrative physiology: I. Introduction to the general notions. American Journal of Physiology, 233, R171-R180.

IBERALL, A. S., \& MCCuLLOCH, W. S. (1969). The organizing principle of complex living systems. Journal of Basic Engineering, 19, 290-294.

Jacobs, D. M., \& Michaels, C. F. (2002). On the apparent paradox of learning and realism. Ecological Psychology, 14, 127-139. doi:10.1207/S15326969ECO1403_2

JaCoBs, D. M., \& Michaels, C. F. (2007). Direct learning. Ecological Psychology, 19, 321-349.

Jacobs, D. M., Runeson, S., \& Michaels, C. F. (2001). Learning to visually perceive the relative mass of colliding balls in globally and locally constrained task ecologies. Journal of Experimental Psychology: Human Perception \& Performance, 27, 1019-1038. doi:10.1037/0096 $-1523.27 .5 .1019$

Jacobs, D. M., Silva, P. L., \& Calvo, J. (2009). An empirical illustration and formalization of the theory of direct learning: The musclebased perception of kinetic properties. Ecological Psychology, 21, 245-289.

Kingma, I., BeEK, P. J., \& van DieËN, J. H. (2002). The inertia tensor versus static moment and mass in perceiving length and heaviness of handwielded rods. Journal of Experimental Psychology: Human Perception \& Performance, 28, 180-191. doi:10.1037/0096-1523.28.1.180

Lederman, S. J., \& KlatzKy, R. L. (1987). Hand movements: A window into haptic object recognition. Cognitive Psychology, 19, 342368. doi:10.1016/0010-0285(87)90008-9

Lederman, S. J., \& KlatzKy, R. L. (1990). Haptic classification of common objects: Knowledge-driven exploration. Cognitive Psychology, 22, 421-459. doi:10.1016/0010-0285(90)90009-S

LEMPEL, A., \& ZIV, J. (1976). On the complexity of finite sequences. IEEE Transactions on Information Theory, 22, 75-81.

Michaels, C. F., Arzamarski, R., Isenhower, R. W., \& Jacobs, D. M. (2008) Direct learning in dynamic touch. Journal of Experimental Psychology: Human Perception \& Performance, 34, 944-957. doi:10.1037/0096-1523.34.4.944

Michaels, C. F., \& Carello, C. (1981). Direct perception. Englewood Cliffs, NJ: Prentice Hall.

Michaels, C. F., \& DE VRies, M. M. (1998). Higher order and lower order variables in the visual perception of relative pulling force. Journal of Experimental Psychology: Human Perception \& Performance, 24, 526-546. doi:10.1037/0096-1523.24.2.526

Michaels, C. F., Weier, Z., \& Harrison, S. J. (2007). Using vision and dynamic touch to perceive the affordances of tools. Perception, 36, 750-772. doi:10.1068/p5593

Riley, M. A., Wagman, J. B., Santana, M. V., Carello, C., \& TurVEY, M. T. (2002). Perceptual behavior: Recurrence of a haptic exploratory procedure. Perception, 31, 481-510. doi:10.1068/p3176

RUNESON, S. (1977). On the possibility of "smart" perceptual mechanisms. Scandinavian Journal of Psychology, 18, 172-179. doi:10.1111/j.1467-9450.1977.tb00274.x

Shaw, R. E., \& McInTYRE, M. (1974). Algoristic foundations to cognitive psychology. In W. Weimer \& D. Palermo (Eds.), Cognition and the symbolic processes (pp. 305-362). Hillsdale, NJ: Erlbaum.

Smith, M. R. H., Flach, J. M., DitTman, S. M., \& Stanard, T. (2001). Monocular optical constraints on collision control. Journal of Experimental Psychology: Human Perception \& Performance, 27, 395-410. doi:10.1037/0096-1523.27.2.395

Solomon, H. Y., \& TuRveY, M. T. (1988). Haptically perceiving the distances reachable with hand-held objects. Journal of Experimental Psychology: Human Perception \& Performance, 14, 404-427. doi:10.1037/0096-1523.14.3.404

Stephen, D. G., Arzamarski, R., \& Michaels, C. F. (in press). The role of fractality in perceptual learning: Exploration in dynamic touch. Journal of Experimental Psychology: Human Perception \& Performance.

Stoffregen, T. A., \& Bardy, B. G. (2001). On specification and the senses. Behavioral \& Brain Sciences, 24, 195-261. doi:10.1017/ S0140525X01003946

Turvey, M. T. (1988). Simplicity from complexity: Archetypal action regimes and smart perceptual instruments as execution-driven phenomena. In J. A. S. Kelso, A. Mandell, \& M. F. Schlesinger (Eds.), Dynamic patterns in complex systems (pp. 327-347). Singapore: World Scientific.

Turvey, M. T. (1996). Dynamic touch. American Psychologist, 51, 1134-1152. doi:10.1037/0003-066X.51.11.1134

Turvey, M. T., Burton, G., Amazeen, E. L., Butwill, M., \& Carello, C. (1998). Perceiving the width and height of a handheld object by dynamic touch. Journal of Experimental Psychology: Human Perception \& Performance, 24, 35-48. doi:10.1037/0096 $-1523.24 .1 .35$

Turvey, M. T., Carello, C., \& Kim, N.-G. (1990). Links between active perception and the control of action. In H. Haken \& M. Stadler (Eds.), Synergetics of cognition (pp. 269-295). Berlin: Springer.

TurveY, M. T., \& Shaw, R. E. (1995). Toward an ecological physics and a physical psychology. In R. L. Solso \& D. W. Massaro (Eds.), The science of mind (pp. 144-169). New York: Oxford University Press.

Turvey, M. T., \& Shaw, R. E. (1999). Ecological foundations of cognition: I. Symmetry and specificity of animal-environment systems. Journal of Consciousness Studies, 6, 95-110.

\section{NOTES}

1. Intention, so formulated, plays the role in an ecological approach to perception-action that concept plays in more traditional cognitive science in that it provides the perceiver's means of perception (Turvey $\&$ Shaw, 1995, 1999). The education of intention is also an informationguided process. "An animal detects invariants over time that specify continuing entities and it detects invariants over entities that specify ecologically reliable partitionings" (1999, p. 107). The latter process, detecting invariants over entities, underlies the ability to distinguish dif- 
ferent properties and different kinds - that is, what might be interpreted as concepts.

2. Although we take Jacobs and Michaels's (2007) information space as our departure point, we note that other theoretical approaches, such as probabilistic functionalism, Bayesian theory, connectionist theory, and other species of cue combination, have implicit or explicit concepts analogous to information space, as well as processes that would move learners through the space.

3. For now, we construe this claim narrowly. We limit ourselves to candidate variables for a single perceptual system - in this case, dynamic touch. Similarly, we limit our study to the case where the change of intention is to a similar property, such that the intentional switch would not bring one out of the information space. Eventually, these simplifying assumptions should be relaxed, perhaps to admit a global (multisensory) array (Stoffregen \& Bardy, 2001) and to admit leaps to other spaces.

4. We define the information function in terms of angle, $\alpha$, instead of a linear $\alpha$, as was done by Michaels et al. (2008), who projected redundant points onto a line instead of a circle.

5. We did not include a control group that received no feedback because we had shown in our previous work that participants who do not receive feedback move significantly less on the information line and do not approach the optimum over blocks (Michaels et al., 2008).
6. There were, of course, changes in scaling, too. The average gains (and standard deviations over participants) as a function of block were $.711(.165), .827(.124), .787(.176), .827(.086)$, and $.329(.121)$ for the $\mathrm{W} \rightarrow \mathrm{L}$ condition, and .289 (.278), .331 (.252), .449 (.162), .469 (.200), and $.718(.305)$ for the $\mathrm{L} \rightarrow \mathrm{W}$ condition.

7. Values of $\alpha$ can also be found by regressing $\ln$ (judgments) against $\ln \left(I_{1}\right)$ and $\ln \left(I_{3}\right)$ and finding the angle whose tangent is the ratio of the coefficients of $\ln \left(I_{1}\right)$ and $\ln \left(I_{3}\right)$.

8. Our main interest is in the direction of the applied muscular torques, which determines the parts of the inertia tensor that are revealed. These torques are the primary determinants of the directions of motion that are observed. We ignored velocities and accelerations, because these depend not only on the torques applied by the participant, but also (and profoundly) on the inertial properties of the object. Given our interest in direction of movement, we were also less interested in measures of recurrence and systematicity, which have been used by others in the dynamic touch paradigm (e.g., Riley et al., 2002). We report the fractality of these exploratory movements elsewhere (Stephen, Arzamarski, \& Michaels, in press).

9. Inverting Figure 2 does not properly portray the basins of attraction for the theory of direct learning; specification of an attractor basin requires a candidate information variable (see Jacobs et al., 2009, or Michaels et al., 2008). For a model of learning that depends on local slope, an inverted Figure 2 might well be an accurate attractor model.

\section{APPENDIX}

\section{Movement Analysis}

Figure A1 presents two plots each of three trials from Block 4. They were chosen to illustrate a range of exploratory styles, the method of segmentation, and comparisons of the two segmentations. The left panels show the successions of momentary angles. The segmentations of trials into bouts were done using the time series of the same angles, shown on the right.

The top-most panels show primarily AP movements and a separate bout of twisting, seen as the clump in the left panel and as large blue oscillations on the right. The two segmenters agreed well on the segmentation points. The categorization algorithms identified this trial as containing AP movement, twist, and oscillation, but no LR or circular movement.

The middle panels illustrate a very simple exploration, consisting of a twisting oscillation, accomplished by repeated flexion/extension of the wrist. There appears to be left-right movement, but this is an artifact of the fact that the object moves to the left when the wrist is flexed, and to the right when the wrist is extended. (As is obvious from Figure 8, we defined LR movements in terms of pronation/supination.) Again, the segmenters agreed on the segmentation that there was only one bout. The categorization algorithms identified this trial as containing only twist and oscillation.

The bottom panels illustrate large AP rotations and large LR rotations, made more or less together. These large LR rotations are done with wrist pronation and supination and are much larger than those from flexionextension. The two segmentations differed. The top segmenter identified three segments, whereas the bottom segmenter identified only two. The categorization algorithms identified this trial as containing circular movements and oscillation, but no twist. 


\section{APPENDIX (Continued)}
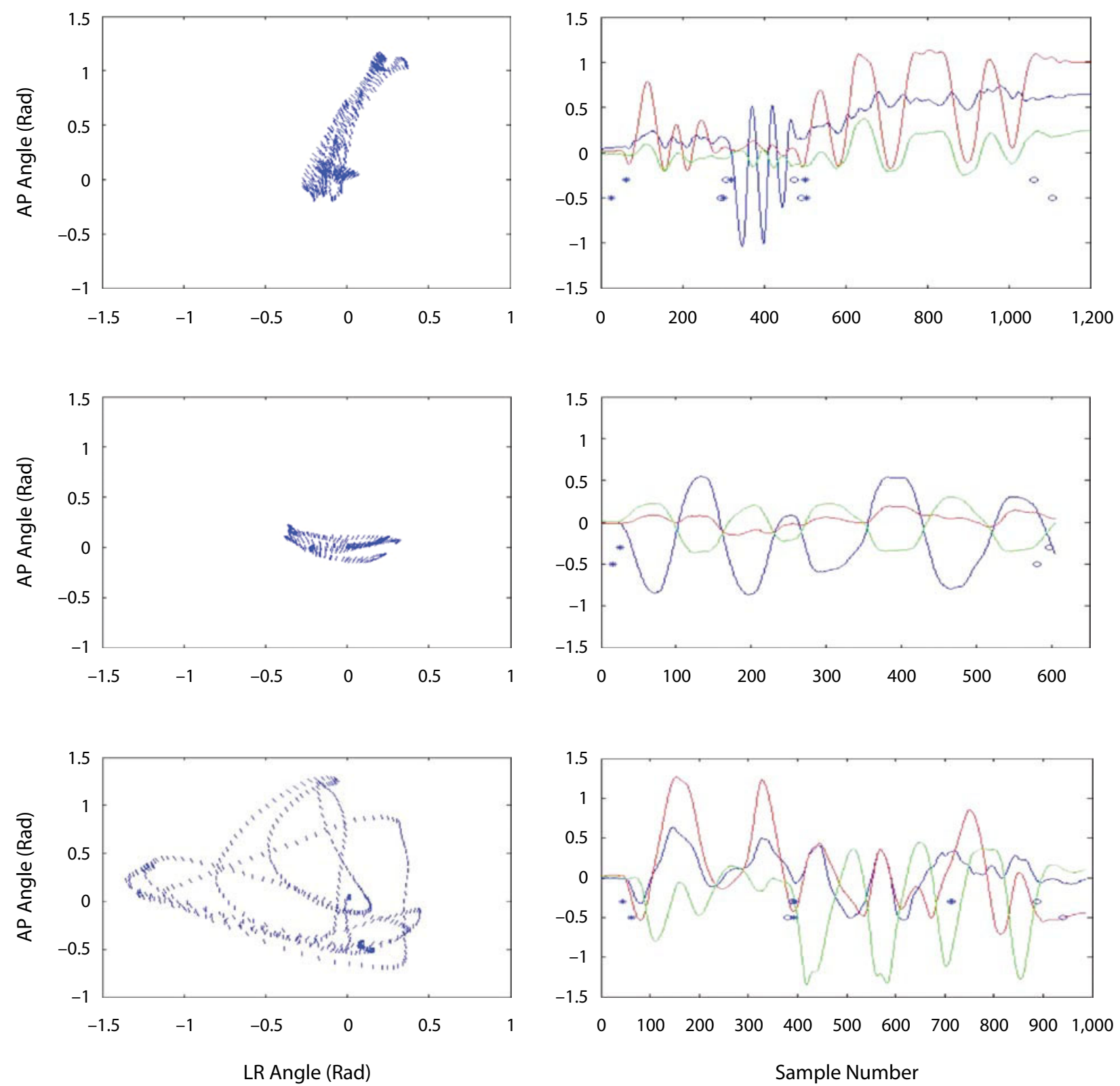

Figure A1. Three trials of wielding from Block 4; the top trial is from a participant reporting length; the bottom two are from participants reporting width. For the left panels, the abscissa represents the left-right (LR) angle; the ordinate represents the anteriorposterior (AP) angle; and the orientation of the bar represents the twist angle. The successive bars correspond to successive samples in the 120-Hz time series. The right panels show the time series of the same data, with the green lines representing the $L R$ angle, the red lines representing the AP angle, and the blue lines representing the twist angle. Overlaid on the time series are the results of the two segmentations, one above the other. The asterisks denote the start of an identified segment; the circles denote the ends of the identified segments. Note that the times on the right plots are not to the same scale.

(Manuscript received September 8, 2009;

revision accepted for publication November 13, 2009.) 